\title{
Clinical peculiarities of measles in children from the Ternopil region, Ukraine
}

\author{
Halyna Pavlyshyn, Ivanna Horishna \\ Department of Pediatrics, Ivan Horbachevsky Ternopil National Medical University, Ternopil, Ukraine
}

\section{ABSTRACT}

The medical cards of children hospitalised in the Infectious Department of Ternopil Children's Hospital were analysed. Children, mainly unvaccinated or incompletely vaccinated, form the majority in the structure of measles morbidity in the Ternopil region of Ukraine. The disease has typical cyclic course with pathognomonic symptoms and is mainly moderate and uncomplicated. Complications are predominantly characterised by respiratory and digestive system involvement. Prolongation of the prodromal period with prodromal rash and shortening or prolongation of the exanthema period in some patients, characterised by specific rash staging, are the main clinical peculiarities in children of this region. Leukopaenia, thrombocytopaenia, eosinophilia, and leukocytic left shift are typical for the prodromal and exanthema period, and normocytosis or leukocytosis with lymphocytosis are typical for the pigmentation period. A biochemical blood test shows the impairment of the liver function in some cases. Chest X-ray shows strengthening of the pulmonary pattern in the base of the lungs in the case of complications with bronchitis and infiltrates in the lower lobes in case of pneumonia.

\section{KEY WORDS:}

measles, children, immunisation, clinical course, complications.

\section{INTRODUCTION}

Measles was one of the most frequent infectious diseases of childhood for many centuries. Immunisation, which was initiated in 1963, decreased the morbidity throughout the world. In Ukraine vaccinations were started in 1966 with booster vaccinations since 1986, which decreased the morbidity rate and prolonged epidemic intervals to 5-6 years. However, measles morbidity increased in 2016-2018 in many countries in the European region, and Ukraine held first place among them. A total of 53,218 Ukrainians were ill in 2018 according WHO data, and 16 cases were fatal. That is $64.67 \%$ of the diseased within the European region. The morbidity rate in that period was 1209.26 per million, which was higher than in Serbia, Georgia, or Albania [1]. Such high figures are not only because of vaccine shortages, but also because of many parents refusing to vaccinate their children. In the period 2006-2016 the percentage of measles vaccinated 12-month-old infants in Ukraine decreased from $98 \%$ to $42 \%$, and booster vaccinated at six years fell from $98 \%$ to $31 \%$ [2]. A measles epidemic in the Ternopil region of Ukraine started in June 2017 and is ongoing. So far, 3,659 cases have been registered for this period, and 2,405 (65.73\%) of them were children.

The aim of this work was to discover and analyse epidemiological, clinical, laboratory, and instrumental peculiarities of measles in children from the Ternopil region of Ukraine in 2018.

\section{ADDRESS FOR CORRESPONDENCE:}

Halyna Pavlyshyn, Department of Pediatrics, Ivan Horbachevsky Ternopil National Medical University, Maidan Voli 1, 46001 Ternopil, Ukraine, ORCID: 0000-0003-4106-2235, e-mail: halynapavlishin@gmail.com 


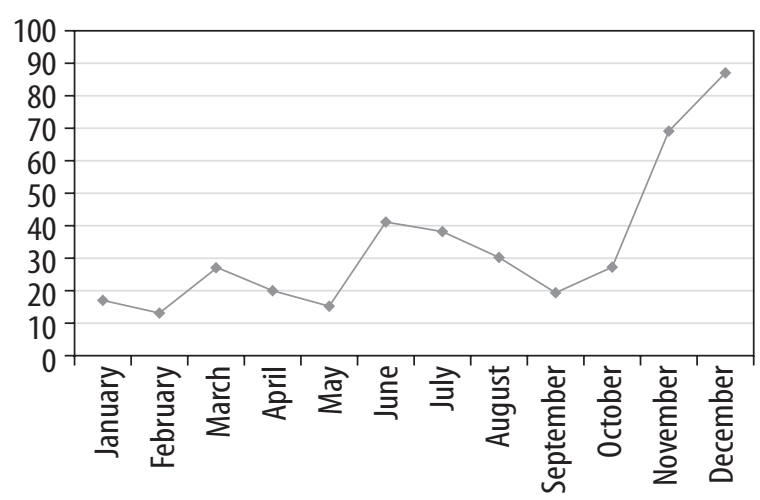

FIGURE 1. Measles morbidity among the patients of the Infectious Department, Ternopil City Hospital, 2018

TABLE 2. Patients' complaints in admission to the Infectious Department, Ternopil City Hospital, 2018

\begin{tabular}{|l|c|c|}
\hline Complaints & Number of cases & Percent of cases \\
\hline High fever & 350 & 86.8 \\
\hline Cough & 398 & 98.8 \\
\hline Nasal congestion & 204 & 50.6 \\
\hline Rhinorrhoea & 148 & 36.7 \\
\hline Conjunctivitis & 305 & 75.7 \\
\hline Rash & 326 & 80.9 \\
\hline Appetite loss & 348 & 86,4 \\
\hline Nausea and vomiting & 12 & 3.0 \\
\hline Stomach ache & 28 & 6.9 \\
\hline Diarrhoea & 108 & 26.8 \\
\hline Hoarseness & 24 & 6.0 \\
\hline Dyspnoea & 74 & 18.4 \\
\hline Fatigue, sleepiness & 228 & 56.6 \\
\hline Total amount & 403 & 100 \\
\hline
\end{tabular}

\section{MATERIAL AND METHODS}

Medical charts of patients treated in the Infectious Department of Ternopil Children's Hospital in 2018 were analysed. Diagnosis of measles was verified by the presence of measles-specific IgM antibodies, detected in the blood serum after three days of exanthema by ELISA. 2017 statistics were taken from the Infectious Department annual report.

\section{RESULTS}

In total 403 children were treated in 2018 in comparison with 67 in 2017; the monthly rate is shown in Figure 1 . Boys comprised $49.4 \%(n=199)$ and girls $50.6 \%$ $(n=204)$. By age, they were represented as follows: infants $14.4 \%(n=58)$, toddlers $15.1 \%(n=61)$, pre-schoolers $20.3 \%(n=82)$, and schoolchildren $50.1 \%(n=202)$. The disease was moderate in $94.5 \%(n=381)$ (complicat-
TABLE 1. Measles complications in the patients of the Infectious Department, Ternopil City Hospital, 2018

\begin{tabular}{|l|c|c|}
\hline Complications & $\begin{array}{c}\text { Number of } \\
\text { cases }\end{array}$ & $\begin{array}{c}\text { Percent } \\
\text { from all the } \\
\text { complications }\end{array}$ \\
\hline Obstructive bronchitis & 65 & 35.1 \\
\hline Pneumonia & 33 & 18.0 \\
\hline Laryngotracheitis & 24 & 13.0 \\
\hline Otitis media & 11 & 6.0 \\
\hline Tubo-otitis & 3 & 1.6 \\
\hline Sinusitis & 2 & 1.1 \\
\hline Aphthous stomatitis & 11 & 6.0 \\
\hline Gastroenteritis & 10 & 5.4 \\
\hline Hepatitis & 8 & 4.3 \\
\hline Pancreatitis & 1 & 0.5 \\
\hline Acute appendicitis & 1 & 0.5 \\
\hline Urinary tract infection & 7 & 3.8 \\
\hline Encephalitic reaction & 3 & 1.6 \\
\hline Encephalitis & 1 & 0.5 \\
\hline Subconjunctival bleeding & 3 & 1.6 \\
\hline Nasal bleeding & 1 & 0.5 \\
\hline Metrorrhagia & 1 & 0.5 \\
\hline Total amount & 185 & 100 \\
\hline
\end{tabular}

ed in $33.6 \%$ of them) and severe in $5.5 \%(n=22)$; in all severe cases measles had complicated course. 185 complications were seen in $37.2 \%(n=150)$ of patients generally because some children had more than one. The range of complications is demonstrated in Table 1.

The complaints, present on admission, are shown in Table 2 .

The percentage of children hospitalised during the prodromal period of measles was $15.4 \%(n=62)$, during the period of exanthema $-83.4 \%(n=336)$, and during the pigmentation period $-1.2 \%(n=5) .48 .6 \%(n=196)$ of children were not vaccinated by measles vaccine, $25.6 \%$ ( $n=103)$ were vaccinated only once, and $25.8 \%(n=104)$ were completely vaccinated. The high percentage of vaccinated children among the diseased can be explained by unsatisfactory documentation of vaccination (fictitious records), which is one of the main problems of primary healthcare in our country.

The prodromal period of measles lasted 2-6 days (mainly 3 to 4$)$ in $71.0 \%(n=286)$. The disease had an acute beginning from high-grade fever in $52.6 \%(n=212)$ or moderate in $44.7 \%(n=180)$, which decreased to lowgrade in $60.8 \%(n=245)$ or normal in $6.2 \%(n=25)$ in the last 1-2 days of this period.

Catarrhal syndrome, initially manifested with mild non-productive cough, started mainly on the second day in $59.1 \%(n=238)$. Rarely cough was a single first sign 


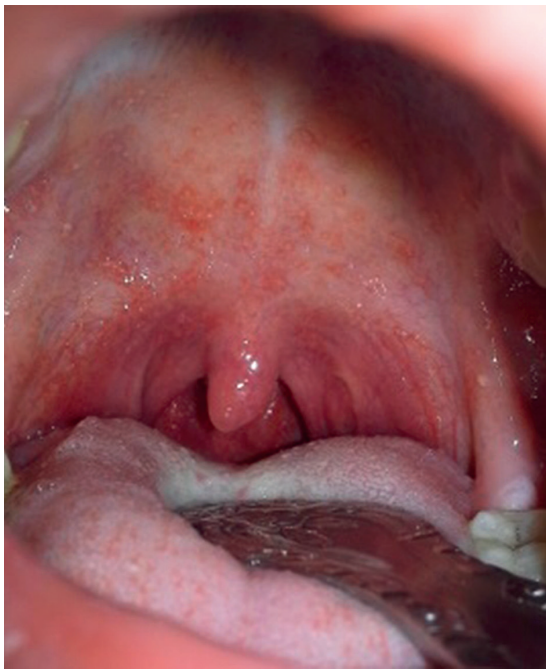

FIGURE 2. Enanthema on the palate

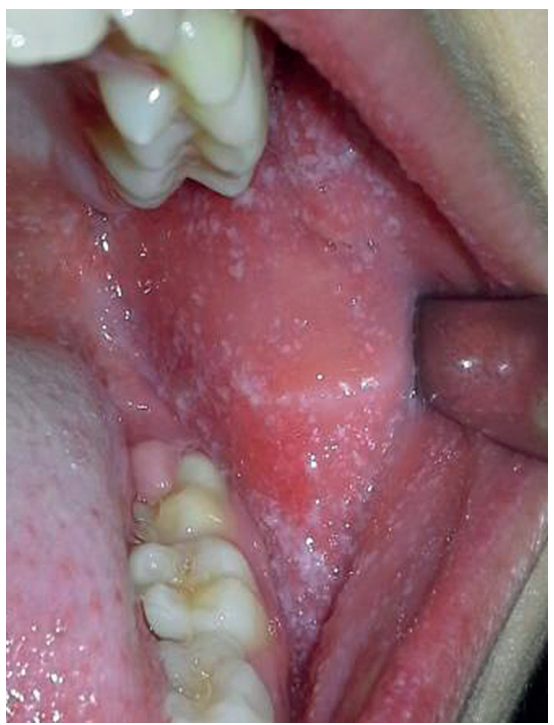

FIGURE 4. Koplik's spots on the $5^{\text {th }}$ day of the disease

of the disease $-3.0 \%(n=12)$, or it appeared at the end of the prodromal period $-17.9 \%(n=72)$. Coryza and conjunctivitis manifested on the $3^{\text {rd }}$ or on the $4^{\text {th }}$ day in $56.1 \%(n=226)$, rarely together with the cough on the second day in $15.6 \%(n=63)$, or at the beginning of the exanthema period $-9.4 \%(n=38)$.

Throat inspection in children hospitalised in the first day of the catarrhal period showed anterior palatine arch and back pharyngeal hyperaemia (without special hallmarks). On the second day, maculous enanthema appeared on the soft palate near the uvula base (Fig. 2); on the $3^{\text {rd }}$ day it transmitted all over the palate and Koplick's spots appeared on the cheeks of the mucosa with their typical localisation opposite the molars (Fig. 3). On the $4^{\text {th }}$ day enanthema increased and formed total hyperaemia; Koplick's spots increased in amount, covered not only the cheeks, but also the lips, gums, and even the palate (Fig. 4). They were also present on the genital mucosa,

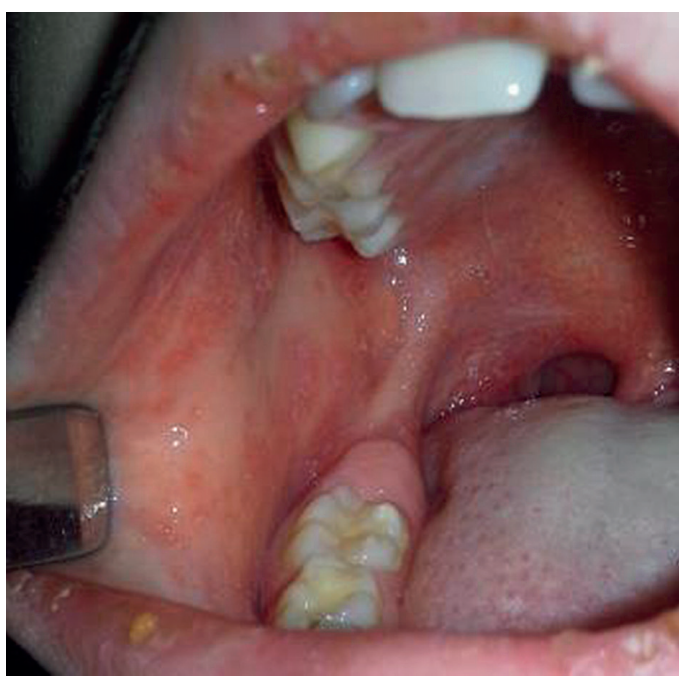

FIGURE 3. Koplik's spots on the $3^{\text {rd }}$ day of the prodromal period

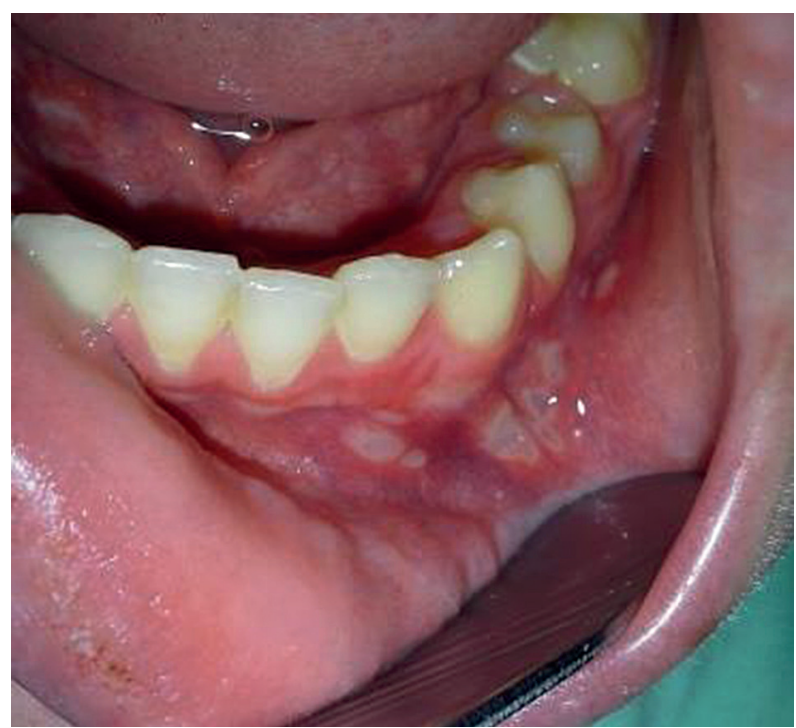

FIGURE 5. Aphthae on the $5^{\text {th }}$ day of the disease

which was accompanied with burning or itching in some cases. The tongue was coated throughout the prodromal period. Several patients $(n=11[2.7 \%])$ had aphthous stomatitis (Fig. 5), sometimes mimicked with Coxsackie stomatitis.

In some cases $(n=26[6.5 \%])$ a prodromal rash was noted in this period. On the $3^{\text {rd }}-5^{\text {th }}$ day, it was seen on the trunk, neck, and hands, appearing with fever and disappearing when the temperature became normal. Those children had a longer (5 to 6 days) prodromal period.

The period of exanthema manifested with rash in 99.8\% $(n=402)$ (the rash was absent in one newborn child only), a second wave of a high grade fever $\geq 39^{\circ} \mathrm{C}$ in $60.0 \%(n=242)$, and even $\geq 40^{\circ} \mathrm{C}$ in $11.2 \%(n=45)$. Catarrhal signs became more severe. For 2-3 days the fever remained high, then decreased to low grade on the $3^{\text {rd }}-4^{\text {th }}$ day of the exanthema period in uncomplicated cases $(n=255[63.3 \%])$. 


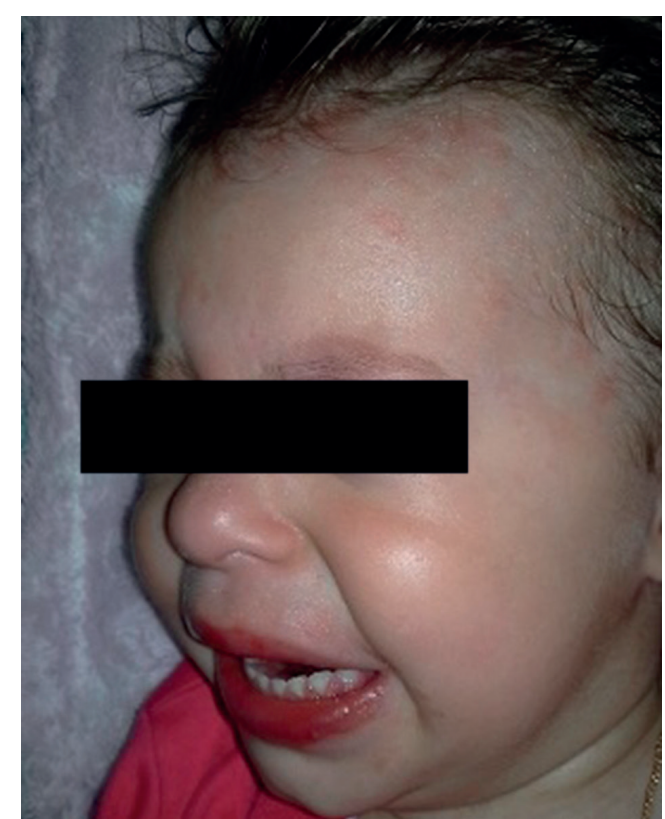

FIGURE 6. Initial localisation of the rash in measles, exanthema period

Typical rash primarily was located on the cheeks and nasal bridge was seen in $36.2 \%(n=146)$, on the back of the ears in $35.7 \%(n=144)$, on the forehead, near the hair line in $23.6 \%(n=95)$ (Fig. 6). Rash had typical three days of staging in $66.5 \%(n=268)$ of patients, was bright red and maculopapular (Fig. 7). In this case it covered the face, neck, and the upper part of the chest on the first day, spread to the whole trunk, arms, and upper part of the thighs on the second day, and all over the body on the $3^{\text {rd }}$ day. Rarely the rash spread for two days $(n=78$ [19.4\%]), covering the face, neck, trunk, and the proximal parts of the arms on the first day and the rest of the body on the second day. In some patients $(n=36$ [8.9\%]), the rash had four days of staging, which on the $1^{\text {st }}-2^{\text {nd }}$ days was typical, appeared on the knees and feet on the $3^{\text {rd }}$ day, and covered the whole body on the fourth day. In some cases $(n=18[4.5 \%])$ this variant of rash staging stopped in three days, so the thighs and shins remained free of rash. A considerable number of patients ( $n=96$ [23.8\%]) complained of itching skin.

Koplick's spots in this period were present in $93.3 \%$ $(n=376)$ of children. They were absent only in infants younger than three months of age $(n=9[2.2 \%])$ and those hospitalised on the $3^{\text {rd }}$ day of exanthema, or later. Throat hyperaemia decreased at the end of the exanthema period and the tongue lost its coating and became "strawberry" sometimes $(n=69$ [17.1\%]). Catarrhal signs stayed the same. Neck and occipital lymph nodes were palpable in $85.6 \%$ $(n=345), 0.5-0.8 \mathrm{~cm}$ in size, movable, elastic, and painless.

The pigmentation period started when the rash became purpuric, brownish, lost its papularity in the same way that it had appeared, frequently ( $n=264$ [65.5\%]) with the haemorrhagic component of different severity (Fig. 8). In many cases $(n=252$ [62.5\%]) epidermis

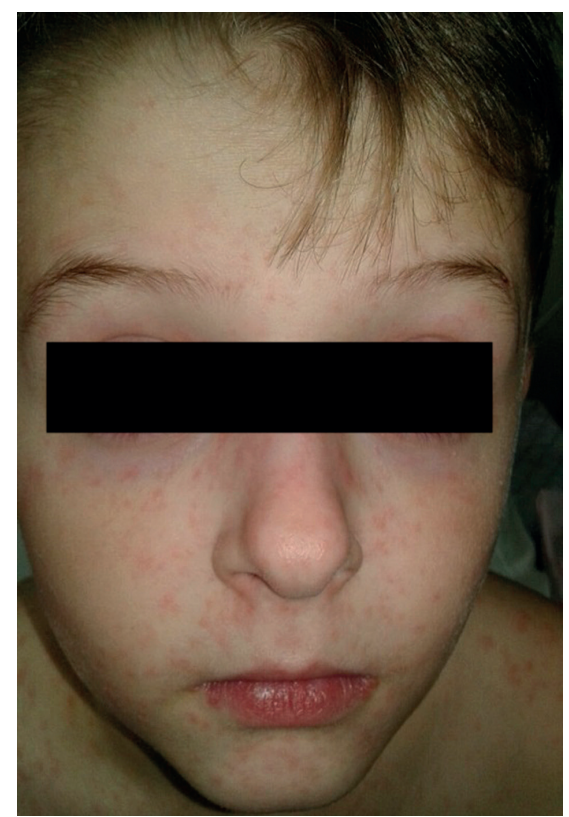

FIGURE 7. Typical morphology of the rash in measles

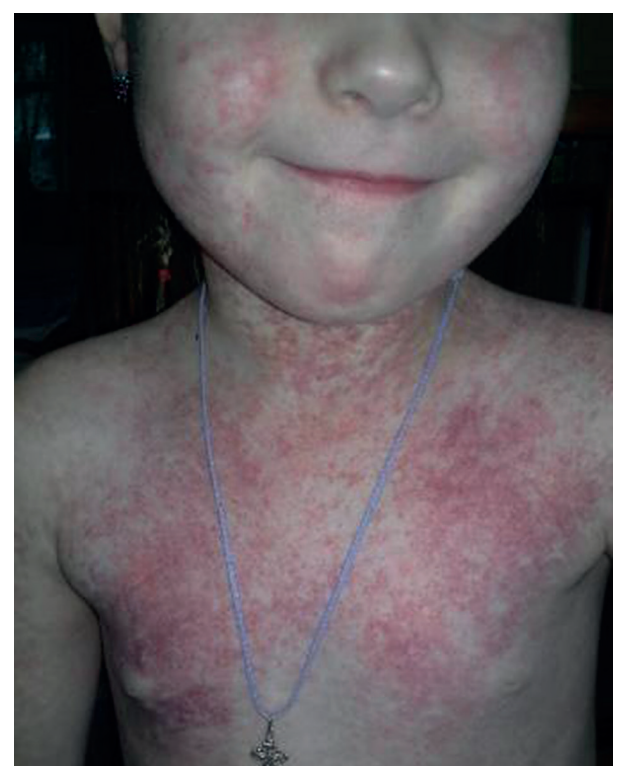

FIGURE 8. Rash pigmentation with severe haemorrhagic component in measles

desquamation was present on the face and neck (Fig. 9). Conjunctivitis, rhinitis, and diarrhoea disappeared at the beginning of the pigmentation period ( $n=348$ [86.4\%]). Cough became less frequent and more productive in $60.0 \%(n=242)$ and disappeared without phlegm production in $38.7 \%(n=156)$ of patients.

Chest percussion in uncomplicated cases (254) revealed resonant sound. Chest auscultation of the same patients revealed harsh breathing in $89.0 \%$ of them $(n=226)$ in prodromal period or in the beginning of exanthema period, inconstant diffuse tiny rales in $58.7 \%$ of cases $(n=149)$ in the end of exanthema period or in the beginning of pigmentation period. 


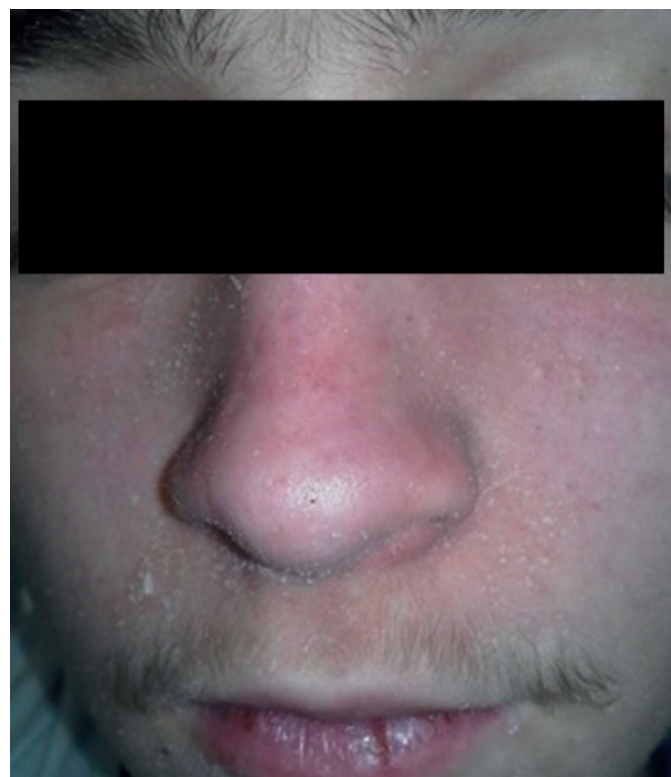

FIGURE 9. Epidermis desquamation on the face in measles, pigmentation period

Complete blood count (CBC) revealed leucopaenia $1.8-3.9 \mathrm{G} / \mathrm{l}(n=176[43.7 \%])$, rarely - leukocytosis $(n=68[16.9 \%])$ or leukemic reaction by lymphocytic type $(n=8[2.0 \%])$, eosinophilia ( $n=268[66.5 \%])$, neutrophilic left shift up to $42 \%$ of immature neutrophils ( $n=345$ [85.6\%]), thrombocytopaenia 32-150 G/l ( $n=198$ [49.1\%]), and lymphocytosis $(n=376$ [93.3\%]). Leucopaenia, thrombocytopaenia, eosinophilia, and neutrophilic left shift were mainly seen in the prodromal period or period of exanthema $(n=278$ [69.0\%]), and normocytosis or leukocytosis with lymphocytosis in the pigmentation period ( $n=376$ [93.3\%]). Biochemical blood test revealed liver function impairment (cytolysis syndrome) in $7.9 \%(n=32)$. Chest X-ray showed strengthening of the pulmonary pattern in the basal parts of the lungs $(n=65[16.1 \%])$ in the case of bronchitis and infiltrates in the lower lobes $(n=33[8.2 \%])$ in the case of pneumonia.

\section{DISCUSSION}

The WHO experts state that any person with fever, maculopapular rash and cough, coryza, or conjunctivitis is considered to be a clinical case of measles [3].

Epidemiological anamnesis (contact with an ill person, air-droplet transmission, and autumn-winter seasonality) is one of the diagnostic criteria of measles. $52.6 \%$ $(n=212)$ of our patients had proven direct contact with an ill person (in the family, in the child's collective, or in a hospital). The percentage of proven direct contact was not very high because of possible infection in out-hospital or nonspecialised hospital departments, where patients with measles in the prodromal period were examined or hospitalised. Grammens et al. (2017) reported low vaccination coverage of patients, high percentage of household or nosocomial measles infection in the period 2016-2017 in Belgium [4].

More than $50 \%$ of ill children in the Ternopil region of Ukraine were younger than six years old, as opposed to $73 \%$ of those older than 15 years in Italy in 2017 or $73.3 \%$ 12-29 years old in Shri-Lanka in 2013 [5, 6]. These statistics could be explained by the low immunisation coverage of children in Ukraine [7].

The average course of hospital treatment was 6.32 days. Patients with moderate measles $(94.5 \%)$ or severe measles (5.5\%) were hospitalised. Absence of mild cases among those treated in hospital could be explained by the fact that they did not need hospitalisation because their disease had an uncomplicated course, as Filia et al. considered, or because the typical course of measles is rarely mild in children [8].

The cyclic course of measles is the next diagnostic criterion of measles. The incubation period in our patients was mainly short (9-11 days) in $82.1 \%$. This could be explained by close contact in families or in hospital. $15.4 \%$ of patients were hospitalised in the prodromal period, which lasted for 2-6 days. It is usually longer in unvaccinated persons [9]. Intoxication and a high fever are the first signs in this period. Catarrhal syndrome is the next: dry, rare than frequent cough accompanied by sore throat, and hoarseness in some patients; rhinitis (nasal congestion or coryza); and conjunctivitis (eyes reddening, photophobia, foreign body sensation, oedema of the eyelids). Vomiting, diarrhoea, and abdominal pain in this period develop because of gastrointestinal mucosa inflammation. Enanthema (rash on palate) and Koplick's spots that appear on the $2^{\text {nd }}-3^{\text {rd }}$ day of illness and increase the next day are specific signs of this period. Premaratna et al. described the presence of Koplick's spots from the $3^{\text {rd }}-4^{\text {th }}$ day of measles [10].

The exanthema period begins with a pinkish maculous rash on the face and backs of the ears, changing to reddish maculopapular and spreading downwards for 2-4 days on the background of high fever (second wave) and catarrh intensification. Typical rash with staging was seen in $99.8 \%$ of our patients. It was absent only in one newborn (two weeks old) (among three), who had contact with an ill mother after birth, presented catarrh and low-grade fever, and had a positive ELISA test with measles-specific IgM antibodies.

The rash usually begins on the $3^{\text {rd }}-5^{\text {th }}$ day of illness and spreads to the $5^{\text {th }}-7^{\text {th }}$ day [9]; it is itchy in some patients [11]. Some of our patients had prodromal rash in the prodromal period that lasted 1-3 days, located on different parts of the body, appeared on the $3^{\text {rd }}-5^{\text {th }}$ day of illness when the body temperature increased, and disappeared when it decreased. Our patients had mainly three-day typical rash staging (66.5\%). Another variant was seen in $19.4 \%$ patients (two stages were passed on the first day), and sometimes four-day staging was present $(8.9 \%)$. Koplick's spots were present in $93.3 \%$ of our 
patients in the period of exanthema and could be seen for no longer than three days of this period. Other authors describe them in $24.2-42 \%$ of patients hospitalised in the period of exanthema $[10,11]$.

Pigmentation period usually begins on the $3^{\text {rd }}-5^{\text {th }}$ day after the rash appears, together with the body temperature normalisation. The rash becomes brownish, and loses its papularity in the same order as it appeared. Some patients have epidermis desquamation on the face and neck. Catarrh gradually disappears for 3-4 days in uncomplicated cases; cough stays longer and becomes less frequent or productive in patients, when they are usually discharged. Lung auscultation shows harsh breathing or unstable bubbling rales in lower lobes of the lungs in the case of productive cough.

In $33.6 \%$ of our patients, measles was complicated. Respiratory complications included laryngotracheitis, obstructive bronchitis, and pneumonia, as could be seen in many publications $[4,6,8$, 9, 12-17]. ENT complications included otitis media and sinusitis, as described in other publications $[8,12,15,18]$. Also, digestive system complications were present, such as gastroenteritis, stomatitis, hepatitis, pancreatitis, and acute appendicitis. The same complications were described by many other authors $[4,6,8,11,12,15,19,20]$. Neurological complications in our patients included one case of encephalitis and febrile seizures in three patients (1.0\%); the same complicated course was described in the literature $[4-6,8,21$, 22 ]. Some cases of haematological complications (nasal bleeding, subconjunctival haemorrhages, metrorrhagia) were caused by thrombocytopaenia. Other authors describe such complications in $3.2-13 \%$ of cases [8, 22].

CBC revealed leucopaenia, thrombocytopaenia, eosinophilia, and leukocytic left shift in the prodromal and the exanthema period; normocytosis or leukocytosis (hyperleukocytosis sometimes) with lymphocytosis in the pigmentation period. Similar haematological signs were described by others $[10,11]$. Biochemical blood test revealed liver function impairment and hyperamylasaemia in some cases, as seen in many publications $[8,10-12,14,15]$.

Chest X-ray showed basal pulmonary pattern intensification in the case of bronchitis, focal or segmental, mainly unilateral, and infiltration with pulmonary pattern intensification in the case of pneumonia. Bilateral pneumonia on X-ray was described by Premaratna et al. [10].

\section{CONCLUSIONS}

Children formed the majority of patients $(65.73 \%)$ in the structure of measles morbidity in 2018 in the Ternopil region of Ukraine. This and the high percentage of vaccinal record falsification explains the necessity for primary care reorganisation in Ukraine.

Despite typical moderate measles in $94.5 \%$ of patients, $37.2 \%$ of cases were complicated - respiratory or diges- tive complications form the vast majority (82.7\%) among them.

Prolongation of the prodromal period of measles up to six days with prodromal rash on the trunk or extremities, shortening of the exanthema period up to two days in $19.4 \%$, or its prolongation up to four days in $8.9 \%$ of patients, characterised by a specific rash staging, and itchy rash in $23.8 \%$ were the main peculiarities of measles, in the 2018 season, among children. We did not investigate clinical peculiarities of measles in vaccinated and unvaccinated children separately. This could be the next step in our work.

Peripheral blood test in the prodromal period of measles and in the period of exanthema is characterised by leukopaenia, thrombocytopaenia, eosinophilia, and a left shift of the leukocytic formula, while in the pigmentation period it is characterised by normocytosis or leukocytosis with lymphocytosis.

Cytolytic syndrome is typical for measles in children.

Intensification of the lung pattern in the base of the lungs on chest X-ray is characteristic for bronchitis and infiltrates in the lower lobes - for pneumonia, as complications of measles in children.

\section{DISCLOSURE}

The authors declare no conflict of interest.

\section{REFERENCES}

1. World Health Organization. WHO EpiData: A monthly summary of the epidemiological data on selected Vaccine-preventable diseases in the WHO European Region. //http://www.euro.who. int/_data/assets/pdf_file/0004/394060/2019_01_Epi_Data_EN_ Jan-Dec-2018.pdf?ua=1

2. Ukraine: WHO and UNICEF estimates of immunization coverage: 2017 revision. //http://www.who.int/immunization/monitoring_ surveillance/data/ukr.pdf.

3. World Health Organization. WHO-recommended surveillance standard of measles. //https://www.who.int/immunization/monitoring_surveillance/burden/vpd/surveillance_type/active/measles_standards/en/

4. Grammens T, Schirvel C, Leenen S, et al. Ongoing measles outbreak in Wallonia, Belgium, December 2016 to March 2017: characteristics and challenges. Euro Surveill 2017; 22: 30524.

5. Lancella L, Di Camillo C, Vittucci AC, et al. Measles lessons in an anti-vaccination era: Public health is a social duty, not a political option. Ital J Pediatr 2017; 43: 102.

6. Dahanayaka NJ, Pahalagamage S, Ganegama RM, et al. The 2013 measles outbreak in Sri Lanka: experience from a rural district and implications for measles elimination goals. Infect Dis Poverty 2015; 4: 51 .

7. Healthcare Ministry of Ukraine, Public Health Centre, Diseases and Information. Immunization Coverage //http://phc.org.ua/pages/ diseases/immunization/immunization-coverage

8. Filia A, Bella A, Del Manso M, et al. Ongoing outbreak with well over 4,000 measles cases in Italy from January to end August 2017 - what is making elimination so difficult? Euro Surveill 2017; 22: 30614. 
9. Mankertz A, Mihneva Z, Gold H, et al. Spread of Measles Virus D4-Hamburg, Europe, 2008-2011. Emerg Infect Dis 2011; 17: 13961401.

10. Premaratna R, Luke N, Perera H, et al. Sporadic cases of adult measles: a research article. BMC Res Notes 2017; 10: 38.

11. Dinh A, Fleuret V, Hanslik T. Liver involvement in adults with measles. Int J Infect Dis 2013; 17: e1243-1244.

12. Grammens T, Maes V, Hutse V, et al. Different measles outbreaks in Belgium, January to June 2016 - a challenge for public health. Euro Surveill 2016; 21: 30313.

13. Anis-ur-Rehman, Siddiqui TS, Idris M. Clinical outcome in measles patients hospitalized with complications. J Ayub Med Coll Abbottabad 2008; 20: 14-16.

14. Leibovici L, Sharir T, Kalter-Leibovici O, et al. An outbreak of measles among young adults: Clinical and laboratory features in 461 patients. J Adolesc Health Care 1988; 9: 203-207.

15. Antona D, Lévy-Bruhl D, Baudon C, et al. Measles Elimination Efforts and 2008-2011 Outbreak, France. Emerg Infect Dis 2013; 19: 357-364.

16. Bassetti M, Schenone E, Calzi A, et al. Measles outbreak in adults in Italy. Infez Med 2011; 19: 16-19.

17. Torner N, Anton A, Barrabeig I, et al. Epidemiology of two large measles virus outbreaks in Catalonia. What a difference the month of administration of the first dose of vaccine makes. Hum Vaccin Immunother 2013; 9: 675-680.

18. Monfort L, Muñoz D, Trenchs V, et al. Measles outbreak in Barcelona. Clinical and epidemiological characteristics. Enferm Infecc Microbiol Clin 2009; 28: 82-86.

19. Sutherland AG, Barnabas K, Haribhaskar K. Measles: an adult case during a local outbreak. BMJ Case Rep 2009; pii: bcr02.2009.1559.

20. Fusilli G, De Mitri B. Acute pancreatitis associated with the measles virus: case report and review of literature data. Pancreas 2009; 38 : 478-480.

21. Perry RT, Halsey NA. The Clinical Significance of Measles: A Review. J Infect Dis 2004; 189: S4-S16.

22. Casanova-Cardiel LJ, Hermida-Escobedo C. Measles in the young adult. Clinical features of 201 cases. Rev Invest Clin 1994; 46: 93-98. 